\title{
Interference in identifying attributes and attribute names
}

\author{
BENJAMIN W. WHITE 1 \\ SAN FRANCISCO STATE COLLEGE
}

\begin{abstract}
The interference of incongruous attribute names on attribute identification was studied with two different attributes, color and direction, and with two modes of identifying response, verbal and nonverbal. Nonverbal responses made for less interference under all conditions. Semantic proximity produced more interference with color than with direction. Interference in this sort of task may reflect characteristic ways in which incoming attribute information is processed.
\end{abstract}

Interest in the Stroop (1935) color-word interference test was revived recently when Klein (1964) demonstrated that the difficulty in naming hues increased directly with the semantic proximity of the words in which the hues were printed. Interference was maximal when the words were the actual hue names printed in incongruous hues, minimal when they were unpronounceable nonsense syllables, and intermediate when they were English words unrelated to color. Klein's findings have been independently replicated and elaborated in several subsequent studies (Schiller, 1966; Bakan \& Alperson, 1967; Grand, 1967; Gholson \& Hohle, 1968a).

Though these studies unambiguously establish the relation of interference with semantic proximity, they do not show why it is that an incongruous mixing of hues and hue names makes it difficult to name the hues, but interferes very little with reading the names. The present experiment was designed to see whether or not the effect was due to the fact that a verbal response was being used, and to ascertain whether or not the same sort of interference would be found with an attribute other than color.

Klein $(1964$, p. 577) offers an explanation of the effect based upon the assumption that "the color names and the irrelevant color-words involve identical motor-responses." "Interference from the word consists essentially in the disposition to say it. It is in this sense that we speek of "competition' from the word [ibid., p. 584]."

Klein's motor-competition explanation appears to assume verbal response, though the task could equally well be performed with some other type of response, such as pushing an appropriately color-coded button. Under such circumstances, there would still be competition for the same motor response but it could hardly be argued that the response to the name would have greater strength than the response to the attribute.

There is another peculiarity of the verbal responses that should be made explicit in this type of task. There is a more radically different relationship between the spoken word red and the printed word red than between the same spoken word and the hue of the ink in which the word has been printed. To use Fitts's (1967) term, there is a high degree of stimulus-response compatability in the spoken-printed word situation, and a completely arbitrary relation between the hue and the hue name. This compatability comes about because of the fact that the sequence of letter forms in the printed word is linked in an orderly way to sequence of uttered sounds in the spoken word even though this linkage in English is far from a one-to-one mapping. No such linkage exists between the hue of the ink and the form of the utterance of the hue name. Such compatability may well account for the well-established fact that it takes longer to name a series of attributes than to read a parallel series of attribute names (Gholson \& Hohle, 1968b). One would expect this difference to be sharply reduced if a nonverbal response were used.

It is probably an historical accident that the attribute of color has been used exclusively in this interference task. Analogous tasks could be created using other visual attributes incongruously mixed with their names. Is something unique about color as an attribute in this connection? In the context of multidimensional scaling, Shepard (1964) has drawn a distinction between unitary and analyzable stimuli. The judged similarity of unitary stimuli cannot be accounted for in Euclidian metric space, while the similarity of analyzable stimuli can. Color, according to Shepard, is an attribute associated with unitary stimuli, while such spatial attributes as size or inclination are more typically associated with analyzable stimuli (see also Lockhead, 1966). Would a spatial attribute behave differently in the interference task?

This experiment was designed to see if Klein's obtained relationship of interference to semantic proximity would hold equally well for verbal as for nonverbal responses, and for an attribute other than color.

\section{Subjects}

\section{METHOD}

The $80 \mathrm{Ss}$ in this experiment were undergraduates of Tufts University. They were assigned to the eight experimental groups randomly upon arrival. They were paid for their time.

\section{Procedure}

The Ss were tested individually in a single $1 / 2-\mathrm{h}$ experimental session. There were eight conditions comprising all possible combinations of two attributes (color or direction), two response modes (verbal or button), and two degrees of semantic proximity (incongruous attribute names or nonsense syllables). The basic data recorded for every condition was the time taken to report the attributes of 80 stimuli, presented visually on a lecturn before the $S$ who was seated at a table. The attribute reported was either color-red, blue, green, or yellow-or direction north, east, south, and west. It was reported either by speaking the name of the attribute for each stimulus or by a manual response. In the case of color, the manual response was the pressing of one of four buttons in a horizontal array under the four fingers of the right hand. In the case of direction, there was a short lever projecting from the top of a box placed in front of $S$. This lever was spring-loaded so that it rested normally at the center of a cross and could be moved up, down, to the right, or to the left. These positions were associated with the direction names, north, south, east, and west, respectively.

A S assigned to the condition spatial-nonverbal-attribute name would first be familiarized with the response switch. He was then shown a typed sheet containing a random list of these four words and asked to move the switch in the appropriate direction for each word in turn on the list. He was timed on this "word only" task. He was then given a sheet on which were drawn 40 squares similar to those shown in Fig. 1. In each square, at the top, bottom, right, or left side, a row of asterisks had been typed and the $S$ was asked to look at each box and to move his response switch in a direction corresponding to the position of each set of asterisks. This "attribute-only" trial was also timed. $S$ was then presented with a third sheet containing boxes in which the words 


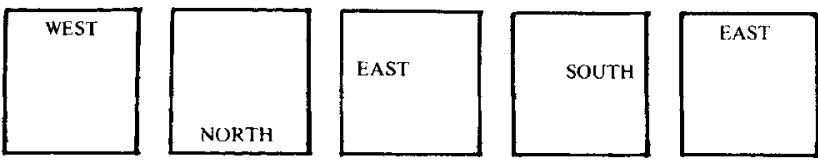

Fig. 1. Sample of incongruous material for the direction attribute.

"north," "east," "south," or "west" had been typed in incongruous positions in boxes. He was instructed to move the response switch in a direction appropriate to the position that the names occupied, regardless of what the name was. Ss in the nonsense-syllable condition performed the same task except that in place of the words north, east, south, and west, one of four nonsense syllables had been typed in one of the four positions within the square.

The procedure for the other conditions was similar, with appropriate modifications of stimulus material and pushbuttons for the color attribute. Under every condition $S$ responded first to the attribute name list, then to the attribute-only displays, and finally to the interference condition in which the attributes were carried by incongruous attribute names or by nonsense syllables. The nonverbal response mode for color required an arbitrary pairing of the four pushbuttons with the four hues. Under this condition, each $\mathrm{S}$ was given 10 practice trials with randomly arranged color patches so that he could become somewhat familiar with the color-button pairing. No such practice trials were required for the toggle switch device used for the direction response.

The switches were wired to a card punch in order to record the nonverbal responses. A tape recorder was used to record the verbal responses.

\section{RESULTS}

The mean times taken by the Ss to identify 80 attributes or attribute names under the various experimental conditions are given in Table 1.

Comparing the entries in the first two columns, we find that when the Ss are under instruction to use verbal report they take longer to name attributes than to read attribute names, both for color and for direction. This result is consistent with the reaction time data reported by Gholson and Hohle (1968b). This difference does not hold, however, for nonverbal responses, which took longer under all conditions than the verbal, a result that is hardly surprising in view of the novelty of this response. It was roughly the same for color and direction. The verbal response times were somewhat longer in the direction, attribute-only condition, probably due to unfamiliarity on the part of some Ss with standard map orientation conventions.

Using Schiller's (1966) method, interference scores were determined for each $S$ by computing a ratio of his interference condition time to his time for the attribute-only condition. Ratios greater than 1.00 indicate that the $S$ took longer to identify 80 attributes in the interference condition than on the attribute-alone condition and ratios less than 1.00

Table 1

Mean Time in Seconds to Identify 80 Attributes or Attribute Names $(\mathbf{N}=\mathbf{2 0})$

\begin{tabular}{lcc}
\hline & Name Alone & Attribute Alone \\
\cline { 2 - 3 } Color & 17.6 & \\
$\quad$ Verbal Response & 39.3 & 23.3 \\
$\quad$ Non-Verbal Response & & 37.8 \\
Direction & 19.8 & 33.2 \\
$\quad$ Verbal Response & 36.8 & 34.5 \\
\hline
\end{tabular}

indicate the reverse. A 2 by 2 by 2 analysis of variance was performed on these interference ratio scores. The main effects of semantic proximity $[F(1,72)=145.2, p<.001]$. attribute $[F(1,72)=28.6, p<.001]$, and response mode $[F(1,72)=28.1, \mathrm{p}<.001]$ were all significant. One interaction, semantic proximity-attribute $[F(1,72)=86.2, p<.001]$, achieved significance.

Interference ratios were also computed on the basis of the mean times for each of the eight groups. These interference scores are plotted in Fig. 2.

\section{DISCUSSION}

Once again Klein's findings have been replicated for the color-word task. Degree of interference is highest when the words are the hue names and is almost nonexistent when nonsense syllables are used. This difference is of similar magnitude regardless of the response mode.

Less interference was found with the nonverbal response mode under all conditions. With the nonverbal response mode there was no difference in the speed with which attributes and attribute names could be identified, whereas in the verbal response mode the attribute-name task was performed more quickly both for color and for direction. It thus appears that there may be no basic difference in the speed with which people can respond to attributes or attribute names if one chooses a response that is not more compatible with one aspect of the display than the other. All too frequently in information-transmission experiments, this aspect of S-R compatability is ignored.

These results case some doubt on Klein's explanation of the color-form interference that rests upon an assumption that the S-R bond between printed word and spoken word is much stronger than the bond between hue and the spoken name of the hue. Attribute and word are both competing for the same motor response and the printed-spoken word connection is more insistent. On this basis, Klein would predict little or no interference if a response were used that had not, in the previous

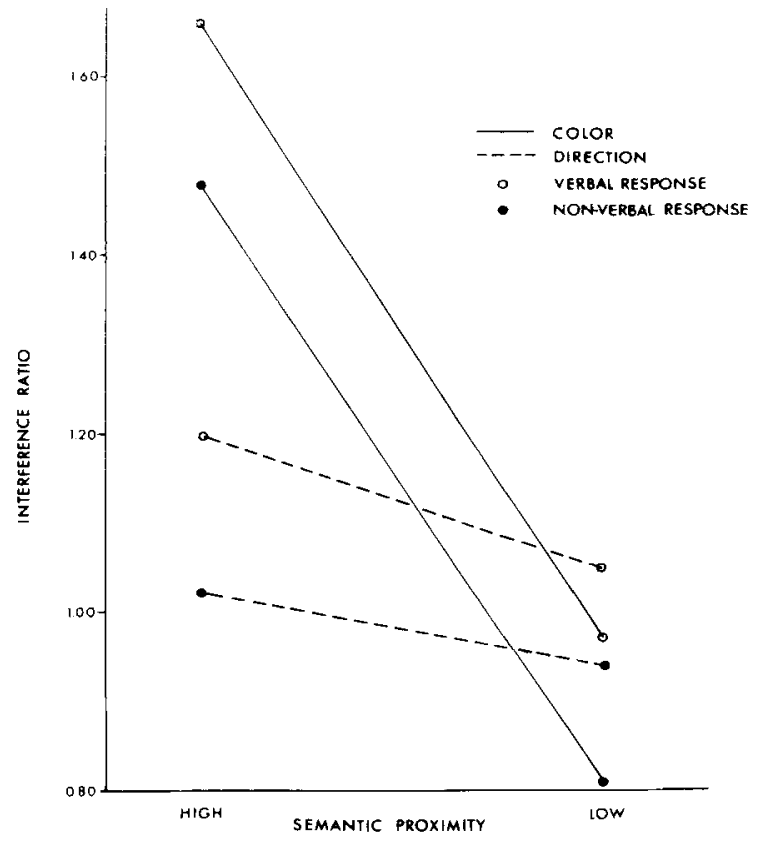

Fig. 2. Interference ratios under two degrees of semantic proximity for two attributes and two modes of identifying response. 
experience of the $S$, been more closely linked with the word than the attribute. Color-word interference was still substantial in the nonverbal response mode, so Klein's rationale cannot be accepted without modification.

These findings, while they cast some doubt on Klein's explanation for color-word interference, do not provide a basis for a clear alternative. However, the fact that interference is more evident with color as an attribute than with direction, suggests that the explanation is more likely to be in terms of the peculiarities of input processing than in terms of response competition. The task used here has a formal similarity to those employed to study selective attention and short-term storage (Broadbent, 1957; Treisman, 1964; Rabbitt, 1962) in that Ss are asked to respond to one aspect of a message while ignoring another. It is possible that the color-word type of task may prove useful to test hypotheses about the nature and sequence of readout from short-term "iconic" memory store. Rabbitt's (1962) experiment suggests that two aspects of a visual stimulus may operate in a manner similar to Broadbent's digits sent to right and left ears. If it should happen that one of these attributes were categorized before the other, then one might expect differential interference if the two were incongruously embodied in a single stimulus pattern. Perhaps this is the case when color and form are pitted against each other, and not so much the case when a spatial attribute such as direction and form are used.

\section{REFERENCES}

BAKAN, P, \& ALPERSON, B. Pronounceability, attensity and interference in the color-word test. American Journal of Psychology, $1967,80,416-420$.
BRoAdBenT, D. E. Perception and communication. Oxford: Pergamon, 1958.

FITTS, P. M., \& POSNER, M. I Human performance. Belmont, Calif.: Brooks/Cole, 1967.

GHOLSON, B., \& HOHLE, R. H. Choice reaction time to hues printed in conflicting hue names and nonsense words. Journal of Experimental Psychology, 1968a, 76, 413-418.

GHOLSON, B., \& HOHLE, R. H. Verbal reaction times to hues vs hue names and forms vs form names. Perception \& Psychophysics, 1968b, 3, 191-196.

GRAND, S. Color-word interference: II. An investigation of the role of vocal conflict and hunger in associative priming. Journal of Experimental Psychology, 1968, 77, 31-40.

KLFIN, G. S. Semantic power measured through the interference of words with color-naming. American Journal of Psychology, 1964, 77, 576-588.

LOCKHEAD, G. R. Effects of dimensional redundancy on visual discrimination. Journal of Experimental Psycliology, 1966, 72, 95-104.

RABBIT, P. M. Short-term retention of more than one aspect of a series of stimuli. Nature, 1962, 195, 102.

SCHILLER, P. H. Developmental study of color-word interference. Journal of Experimental Psychology, 1966, 72, 105-108.

SHEPARD, R, N. Attention and the metric structure of the stimulus space. Journal of Mathematical Psychology, 1964, 1, 54-87.

STROOP, J. R. Studies of interference in serial verbal reactions. Journal of Experimental Psychology, 1935, 18, 643-661.

TREISMAN, A. M. Selective attention in man. British Medical Bulletin $1964,20,12-16$.

NOTE

1. Address: Department of Psychology, San Francisco State College, San F rancisco, California 94132.

(Accepted for publication February 24, 1969.) 